\title{
miR-4486 reverses cisplatin-resistance of colon cancer cells via targeting ATG7 to inhibiting autophagy
}

\author{
WEIWEI WANG ${ }^{1}$, LINXIA CHEN $^{2}$, WENJIN ZHU $^{1}$, XIANJIN HUANG $^{1}$, \\ LIN LIN $^{1}$, ZHENHAO QUAN $^{1}$, KAIYU SUN $^{1}$ and QINGWEN XU ${ }^{1}$ \\ Departments of ${ }^{1}$ Gastrointestinal Surgery and ${ }^{2}$ Operating Room, The Affiliated Hospital of \\ Guangdong Medical University, Zhanjiang, Guangdong 524000, P.R. China \\ Received January 7, 2021; Accepted June 1, 2021
}

DOI: $10.3892 /$ etm.2021.10900

\begin{abstract}
Cisplatin (DDP) resistance is one of the main causes of treatment failure in patients with colon cancer (CC). Autophagy is a key mechanism of resistance to chemotherapy. Since autophagy-related 7 (ATG7) has been reported to be involved in the regulation of autophagy and DDP resistance for lung and esophageal cancer, the present study aimed to explore the functions of microRNA (miR)-4486 in the autophagy-mediated DDP resistance of $\mathrm{CC}$. The expression level of miR-4486 in HCT116, DDP-resistant HCT116 cells (HCT116/DDP), SW480 and DDP-resistant SW480 cells (SW480/DDP) was quantified by reverse transcription-quantitative PCR. Western blotting was utilized to analyze the expression of ATG7, autophagy-related proteins Beclin 1 and LC3-I/II, as well as apoptosis-related proteins Bcl-2, Bax and cleaved-caspase 3 in HCT116/DDP and SW480/DDP cells. The half maximal inhibitory concentration of DDP on all cell lines and the cell viability of HCT116/DDP and SW480/DDP cells were measured using Cell Counting Kit 8 assay. Luciferase assay was used to examine the potential targets of miR-4486 and ATG7. The effects of upregulating mimic miR-4486 expression on the apoptosis and autophagy of HCT116/DDP and SW480/DDP cells were determined by flow cytometry and electron microscopy, respectively. It was found that miR-4486 expression was significantly decreased in HCT116/DDP and SW480/DDP cells compared with that in HCT116 and SW480 cells. Overexpression of miR-4486 could increase the sensitivity of HCT116/DDP and SW480/DDP cells to DDP by reducing cell viability, promoting apoptosis and inhibiting autophagy through downregulating Beclin 1 expression and the LC3-II/LC3-I ratio. Additionally, ATG7
\end{abstract}

Correspondence to: Dr Qingwen Xu, Department of Gastrointestinal Surgery, The Affiliated Hospital of Guangdong Medical University, 57 South Renmin Avenue, Zhanjiang, Guangdong 524000, P.R. China

E-mail: xuqwen@21cn.com

Key words: microRNA-4486, cisplatin resistance, colon cancer, autophagy related 7 , autophagy was identified to be a target gene of miR-4486, where ATG7 overexpression could partially reverse the effects of miR-4486 on cell viability and apoptosis by promoting the formation of autophagosomes. In conclusion, the present results demonstrated that miR-4486 could reverse DDP resistance in HCT116/DDP and SW480/DDP cells by targeting ATG7 to inhibit autophagy.

\section{Introduction}

Colon cancer (CC) is the third most commonly diagnosed cancer worldwide and the second most common cause of cancer-related mortalities worldwide (1). The number of new cases and mortalities of colorectal cancer in China ranks first in the world with 2.7 million new cases and over 1.3 million deaths, which is much higher compared with that in other countries and regions (2). At present, although surgical resection and chemotherapy, such as 5-fluorouracil, cisplatin and oxaliplatin, have proven effective for patients with colon cancer, tumor recurrence and chemoresistance remain a major challenge for the efficacy colon cancer therapy (3). Previous studies have shown that autophagy is closely associated with the occurrence and development of numerous cancer types, including leukemia, renal cell cancer, non-small cell lung cancer, melanoma and advanced solid tumor; furthermore, it has also been found to be an important mechanism underlying resistance to chemotherapy $(4,5)$. Therefore, exploring novel interventions to target autophagy may contribute to improving the efficacy of chemotherapy for CC (6).

MicroRNAs (miRNAs or miRs) are a group of evolutionarily-conserved small RNAs that serve a negative role in gene regulation at post-transcriptional levels (7). miRNAs were previously found to be associated with drug resistance by targeting a wide variety of tumor-related genes in gliomas, including a number of drug resistance-related genes, such as EGFR and p53 (8). Changes in the expression level of a single miRNA can simultaneously influence a diverse range complex molecular pathways (9). Therefore, the possible mechanism underlying miRNA-mediated drug resistance may be associated with a complex series of pathological, physiological and biological processes. A number of miRNAs have been reported to be involved in the occurrence of drug resistance in CC, as follows: miR-140 Blocks $G_{1}$ and $G_{2}$ phase 
arrest to sensitize colon cancer stem-like cells to 5-FU (10), miR-20a targets BCL2-interacting protein 2 to mediate chemotherapeutic resistance to fluorouracil, oxaliplatin and teniposide (11), miR-137 sensitizes resistant cells to oxaliplatin by targeting Y box-binding protein 1 (12) and miR-195 sensitizes resistant cells to doxorubicin by targeting BCL2L2 (13). As such, elucidating the functions of miRNAs in mediating drug resistance may lead to improved therapeutic strategies for CC therapy.

miR-4486 was revealed to be downregulated in glioma tissues and to facilitate gliomagenesis in vivo. The overexpression of miR-4486 was found to attenuate the growth of glioma cells (14). Additionally, miR-4486 was significantly downregulated in patients with chronic obstructive pulmonary disease with eosinophilia and was an indicator of poor prognosis (15). Furthermore, increased expression of miR-4486 was found to be associated with febrile seizures (16). However, to the best of our knowledge, the expression and effect of miR-4486 in $\mathrm{CC}$ have not been previously reported. Autophagy related 7 (ATG7) was reported to be a target of miR-106a that suppresses tumor cell death in colorectal cancer, which was associated with inducing autophagy (17). Notably, researchers have found that autophagy is one of the major factors leading to drug resistance in $\mathrm{CC}$ (18), which indicates that autophagy might be a potential target for DDP-resistance colon cancer. Based on these, the present study was designed to investigate the function of miR-4486 on apoptosis and autophagy in DDP-resistant CC cell lines HCT116/DDP and SW480/DDP.

\section{Materials and methods}

Tissue samples. A total of $40 \mathrm{CC}$ tissues resected between Jan 2014 and Dec 2015 were retrieved from the archives of the Affiliated Hospital of Guangdong Medical University (Zhanjiang, China). Thereinto, 22 males and 18 females (1.22:1) were enrolled in this study, and the median age was 57 years (range, 48-67). Inclusion criteria were: Patients met NCCN colon cancer tumor clinical practice guidelines (19). CT, color Doppler ultrasound and MRI were performed to rule out distant metastasis. According to TNM staging system there were Stage I, II and III. Patients did not receive previous chemotherapy or radiotherapy. Patients were diagnosed for the first time, with detailed clinicopathological data. All the slides of CC tissues were re-evaluated as I III graded CC and independently reviewed by two pathologists according to WHO classifications (20). Exclusion criteria were: Patients without other malignant tumors, hematological diseases; patients with severe complications and immune system diseases; patients with poor treatment compliance caused by severe mental illness; and patients unwilling to participate in the present study. The CC tissues were categorized as favorable prognosis group (DDP-sensitive; survival $>5$ years; $n=20$ ) or unfavorable prognosis group (DDP-resistant; survival $<1$ year; $n=20$ ). Based on the time interval between the last dose of DDP and the diagnosis of recurrence, patients were classified as either DDP-sensitive or DDP-resistant cases; $>6$ months of the time interval indicated DPP sensitivity, while $<6$ months of the interval indicated DDP resistance. The tissues were immediately frozen in liquid nitrogen and stored at $-80^{\circ} \mathrm{C}$ until use. The present study was approved by the local Ethics Committee at The Affiliated Hospital of Guangdong Medical University and all patients provided written informed consent.

Cell culture. The human CC cell lines, HCT116 (cat. no. MXC469) and SW480 (cat. no. MXC368) and the corresponding DDP-resistant cells, HCT116/DDP (cat. no. MXC795) and SW480/DDP (cat. no. MXBC241), were purchased from Shanghai Meixuan Biological Technology Co., Ltd. and cultured in RPMI-1640 medium (Gibco; Thermo Fisher Scientific, Inc.) supplemented with $10 \%$ fetal calf serum (Gibco; Thermo Fisher Scientific, Inc.), $100 \mathrm{U} / \mathrm{ml}$ penicillin and $100 \mathrm{U} / \mathrm{ml}$ streptomycin with $5 \% \mathrm{CO}_{2}$ at $37^{\circ} \mathrm{C}$. For the maintenance of the DDP-resistant phenotype, HCT116/DDP and SW480/DDP cells were constantly treated with $5 \mu \mathrm{g} / \mathrm{ml}$ cisplatin (DDP; Sigma-Aldrich; Merck KGaA).

Cell transfection. HCT116, HCT116/DDP, SW480 and SW480/DDP cells were cultured in the medium supplied with $10 \%$ fetal bovine serum in a moist, wet atmosphere with $5 \%$ $\mathrm{CO}_{2}$ at $37^{\circ} \mathrm{C}$ to a confluence of $70-80 \%$ for $24 \mathrm{~h}$. miR-4486 mimic (5'-ACACTCCAGCTGGGGCTGCGCGA-3'), negative control mimic (NC, 5'-UCACAACCUCCUAGAAAGAGU AGA-3'), pcDNA3.1-ATG7 and cDNA3.1 empty vector (NC vector) were synthesized by Shanghai GenePharma Co., Ltd. Subsequently, they were diluted in OptiMEM (Thermo Fisher Scientific, Inc.) to 10x their final concentrations and were mixed with equal volumes of Lipofectamine ${ }^{\circledR} 2000$ (Invitrogen; Thermo Fisher Scientific, Inc.) according to the manufacturer's protocol. A total of $20 \mathrm{ml}$ of the mixture was added per well of the 96-well plate at room temperature for $10 \mathrm{~min}$, and an $80 \mu \mathrm{l}$ aliquot of cells $\left(5 \times 10^{3}-1 \times 10^{4}\right.$ cells/well $)$ was plated at $37^{\circ} \mathrm{C}$ for $4 \mathrm{~h}$. Cell viability was assessed at $96 \mathrm{~h}$ after transfection by adding $80 \mu \mathrm{l}$ CellTiter-Glo ${ }^{\circledR}$ (Promega Corporation) per well and incubating the plate at room temperature for $10 \mathrm{~min}$. Cells were then harvested for subsequent experiments.

Cell Counting Kit-8 (CCK-8) assay. The four cell lines ( $2 \times 10^{3}$ cells/well) were seeded into 96 -well plates and cultured overnight. HCT116, HCT116/DDP, SW480 and SW480/DDP cells were treated with DDP at a concentration of 1, 3, 9, 27 and $81 \mu \mathrm{g} / \mathrm{ml}$ at $37^{\circ} \mathrm{C}$ for $72 \mathrm{~h}$ to determine the half maximal inhibitory concentration $\left(\mathrm{IC}_{50}\right)$. The effect of miR-4486 on the cell viability of HCT116/DDP and SW480/DDP cells treated with an $\mathrm{IC}_{50}$ concentration of DDP was also determined 1 day after transfection. Next, cells were treated with DDP before $10 \mu \mathrm{l}$ CCK-8 reagent (Beijing Solarbio Science \& Technology Co., Ltd.) was added to each well and cultured further at $37^{\circ} \mathrm{C}$ for $2 \mathrm{~h}$ for the measurement of cell viability. The absorbance of each well at $450 \mathrm{~nm}$ was measured by using a microplate reader (Bio-Rad Laboratories, Inc.). Each concentration was analyzed with six replicates. The cell viability was calculated as: Cell viability $=[\mathrm{A}($ experimental $)-\mathrm{A}($ blank $)] /$ [A(control)-A(blank)]. Cell inhibition=1-cell viability.

Cell apoptosis analysis. HCT116/DDP and SW480/DDP cells ( $2 \times 10^{5}$ cells/well) were cultured in six-well plates, before the miR-4486 mimic, NC mimic and pcDNA3.1-ATG7 were transfected into HCT116/DDP and SW480/DDP cells. After 1 day of transfection, a final concentration of $5 \mu \mathrm{g} / \mathrm{ml}$ DDP was added to the HCT116/DDP and SW480/DDP cells to maintain 
their DDP resistance. At $48 \mathrm{~h}$ post-transfection, the cells were washed with PBS and resuspended in the binding buffer with the final concentration of $5 \times 10^{4}$ cells $/ \mathrm{ml}$, then double-stained with annexin V-FITC and PI reagents (Abcam) at room temperature for $15 \mathrm{~min}$ in the dark. Next, after being washed three times with PBS to remove excess antibodies, the cells were analyzed by flow cytometry using BD FACSCanto II flow cytometer (BD Biosciences). All flow cytometry data were analyzed using FlowJo v10.1 software for Macintosh (FlowJo LLC).

Luciferase assay. The potential target of miR-4486 was predicted using TargetScan v2.0 (http://www.targetscan.org/). The wild-type (Wt) and mutant (Mut)-type sequences of ATG7 3'UTR were inserted into the pSi-Check2 reporter vector. The mutant type 3'UTR sequences of ATG7 contained four nucleotide mutations at the miR-4486 targeting site. Next, 2x10 ${ }^{5}$ cells/well 293 T cells (Procell Life Science \& Technology Co., Ltd.) were seeded into 24-well plates and co-transfected with $5 \mathrm{nM}$ miR-4486 mimic or NC mimic and $160 \mathrm{ng}$ pSI-Check2-ATG7-3'-UTR-Wt or Mut) using Lipofectamine 2000 reagent. After transfection for $48 \mathrm{~h}$, the luciferase activity was measured using a Dual-Luciferase Reporter assay system (Promega Corporation) according to the manufacturer's protocol. The experiment was repeated $\geq$ three times. The ratio of Renilla luciferase to firefly luciferase was calculated for each well.

Reverse transcription-quantitative PCR (RT-qPCR). The expression levels of miR-4486 and ATG7 in tissues and cells were analyzed using RT-qPCR. Briefly, total RNA was extracted from HCT116, HCT116/DDP, SW480 and SW480/DDP cells using TRIzol ${ }^{\circledR}$ reagent (Invitrogen; Thermo Fisher Scientific, Inc.) according to the manufacturer's instructions. cDNA was synthesized from total RNA $(1.5 \mu \mathrm{g})$ using a RevertAid First Strand cDNA Synthesis kit (Takara Bio, Inc.), and the synthesized cDNA was amplified at $42^{\circ} \mathrm{C}$ for $30 \mathrm{~min}$. The sequence of the primers for miR-4486 were forward, 5'-ACACTCCAGCTGGGGCTGCGCGA-3' and reverse, 5'-TGGTGTCGTGGAGTCG-3'. The sequence of the primers for ATG7 were forward, 5'-TGGCTGCTACTTCTGCAATGA TGT-3' and reverse, 5'-TTAGCACAGGGAACAGCGCTC ATGG-3'. PCR reactions were performed using the thermocycling conditions of pre-denaturation at $95^{\circ} \mathrm{C}$ for $5 \mathrm{~min}$, followed by and 40 cycles of $95^{\circ} \mathrm{C}$ for $15 \mathrm{sec}$ and $60^{\circ} \mathrm{C}$ for $1 \mathrm{~min}$ and melt curve analysis. To quantify the expression of miR-4486, cells and tissues were subjected to a RT-qPCR assay with an AceQ qPCR SYBR ${ }^{\circledR}$ Green Master Mix kit (Vazyme Biotech Co., Ltd.) according to the manufacturer's instructions. U6 served as a control. For the detection of ATG7, RT-qPCR was performed using SYBR Green PCR Master mix (Thermo Fisher Scientific, Inc.) in an ABI Step One-Plus Detection system (Applied Biosystems; Thermo Fisher Scientific, Inc.) according to the manufacturer's protocols. $\beta$-actin served as a control. The expression levels of miR-4486 and ATG7 were quantified using the $2^{-\Delta \Delta \mathrm{Cq}}$ method (21).

Western blot analysis. To determine the expression levels of ATG7, Beclin 1, LC3-I, LC3-II, Bax, Bcl-2 and cleaved caspase 3, HCT116/DDP and SW480/DDP cells were lysed with RIPA buffer (Santa Cruz Biotechnology, Inc.). The protein lysates were centrifuged at $15,000 \mathrm{x}$ for $15 \mathrm{mins}$ at $4^{\circ} \mathrm{C}$. The protein concentration was measured by a Pierce BCA protein assay kit (Pierce; Thermo Fisher Scientific, Inc.). Protein samples (50 $\mu \mathrm{g} /$ lane) were separated by $10 \%$ SDS-PAGE and were transferred onto polyvinylidene difluoride membranes. Next, the membranes were blocked with $5 \%$ non-fat milk for $1 \mathrm{~h}$ at room temperature and then incubated with the corresponding primary antibodies, including ATG7 (cat. no. ab52472; 1:1,000; Abcam), Beclin 1 (cat. no. ab210498; 1:1,000; Abcam), microtubule-associated proteins 1A/1B light chain 3B (LC3-I and LC3-II; cat. no. L8918, 1:1,000; Sigma-Aldrich; Merck KGaA), Bax (cat. no. 2772T, 1:1,000; Cell Signaling Technology, Inc.), Bcl-2 (cat. no. ab196495, 1:1,000; Abcam), cleaved caspase 3 (cat. no. ab32042; 1:500; Abcam) and $\beta$-actin (cat. no. ab8227; 1:1,000; Abcam) at $4^{\circ} \mathrm{C}$ overnight followed by incubation with a HRP-conjugated anti-rabbit secondary antibody (cat. no. ab205718, 1:10,000; Abcam) at room temperature for $1 \mathrm{~h}$. Protein expression was detected with a high-sensitivity ECL detection kit (Vazyme Biotech Co., Ltd.). The intensity of the bands was expressed as fold-change by normalizing the data to the values of $\beta$-actin using the ImageJ software (v1.48; National Institutes of Health).

Transmission electron microscopy (TEM) analysis for autophagosomes. HCT116/DDP and SW480/DDP cells were fixed in $2.5 \%$ glutaraldehyde (Wuhan Goodbio Technology Co., Ltd.) for $4 \mathrm{~h}$ at $4^{\circ} \mathrm{C}$, rinsed with PBS and then fixed in $1 \%$ osmium tetroxide (Sinopharm Chemical Reagent Co., Ltd.) in $0.1 \mathrm{M}$ PBS for $1 \mathrm{~h}$ at room temperature. Following dehydration with graded ethanol solutions $(70 \sim 100 \%)$ (Sinopharm Chemical Reagent Co., Ltd.) at room temperature for $10 \mathrm{~min}$ each, the cells were embedded in Epon resin (Epon 812; Nisshin EM Co. Ltd.), and ultrathin sections $(50 \mathrm{~nm})$ of the selected areas were cut using a LKB NOVA ultramicrotome (LKB Bromma; GE Healthcare) and a diamond blade (Daito Me Holdings Co., Ltd.). Cells were then stained with a saturated solution of uranyl acetate in methanol (50:50; Sinopharm Chemical Reagent Co., Ltd.) for $12 \mathrm{~min}$ at $45^{\circ} \mathrm{C}$, followed by incubation in an aqueous solution of concentrated bismuth subnitrate (Sinopharm Chemical Reagent Co., Ltd.) for $10 \mathrm{~min}$ at $25^{\circ} \mathrm{C}$. Subsequently, all the sections were observed under a Hitachi TEM system (Hitachi, Ltd.) at a magnification of $\mathrm{x} 8,000$.

Statistical analysis. Each experiment was performed at least three times, and data are presented as the mean \pm standard deviation. Statistical comparisons between a pair of data were carried out using an Unpaired student's t-test, whilst comparisons among multiple groups were performed using a one-way or two-way ANOVA followed by Tukey's post-hoc tests. GraphPad Prism 7 (GraphPad Software, Inc.) was used to perform statistical analysis and graph constructions. $\mathrm{P}<0.05$ was considered to indicate a statistically significant difference.

\section{Results}

Expression of miR-4486 is decreased in CC tissues with an unfavorable prognosis and in DDP-resistant CC cell lines. To investigate the role of miR-4486 in CC, RT-qPCR 
A

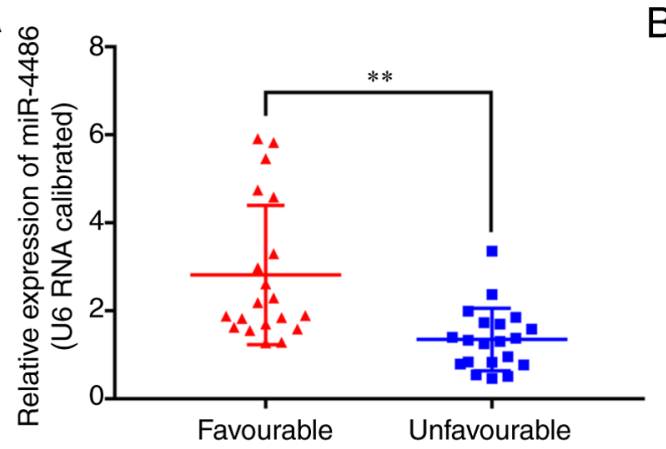

C

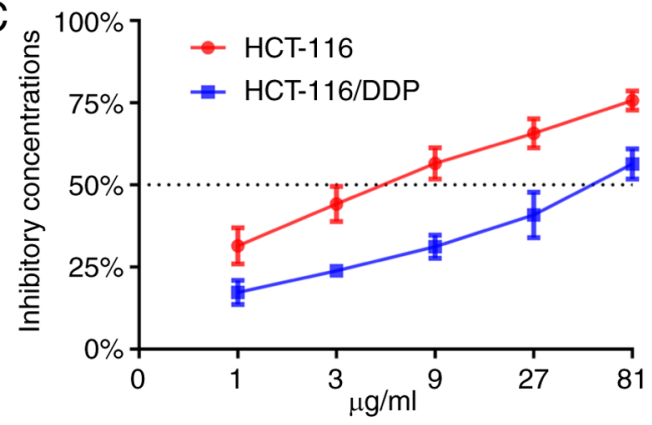

B

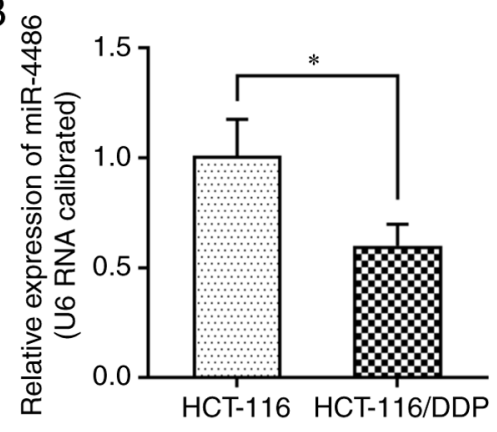

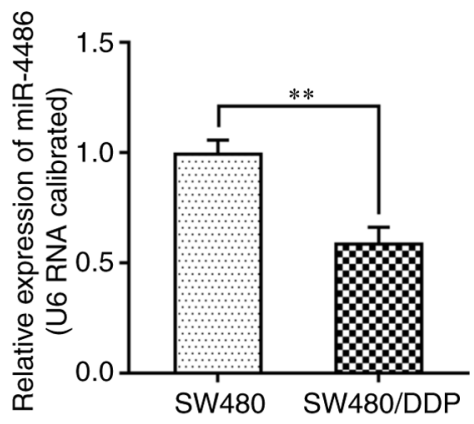

Figure 1. Expression level of miR-4486 is decreased in CC tissues with an unfavorable prognosis and in DDP-resistant CC cell lines. The expression of miR-4486 in (A) CC tissues with a favorable or unfavorable prognosis and (B) all cell lines was determined by reverse transcription-quantitative PCR. (C) The half maximal inhibitory concentration of DDP in HCT and SW480 cells was determined by a Cell Counting Kit- 8 assay. Bars represent the mean \pm standard deviation from $\geq$ three independent experiments. ${ }^{*} \mathrm{P}<0.05,{ }^{* *} \mathrm{P}<0.01$. miR, microRNA; CC, colon cancer; DDP, cisplatin.

was used to quantify the expression of miR-4486 in CC tissues from patients with an unfavorable prognosis and DDP-resistant CC cell lines. It was found that miR-4486 was significantly downregulated in patients with an unfavorable prognosis compared with that in patients with a favorable prognosis (Fig. 1A). There was also a significant reduction in miR-4486 expression in HCT116/DDP and SW480/DDP cells compared with that in their parental HCT116 and SW480 cells (Fig. 1B). CCK-8 assay revealed that the $\mathrm{IC}_{50}$ of DDP in HCT116, HCT116/DDP, SW480, and SW480/DDP cells was 5.5, 52.9, 11.8 and $56.3 \mu \mathrm{g} / \mathrm{ml}$, respectively (Fig. 1C). These results suggest that $\mathrm{miR}-4486$ expression is lower in tissues from patients with $\mathrm{CC}$ with unfavorable outcomes and in DDP-resistant CC cell lines compared with that in the tissues from patients with $\mathrm{CC}$ with favorable outcomes and parental $\mathrm{CC}$ cell lines, respectively.

Overexpression of miR 4486 reverse DDP resistance in HCT116/DDP and SW480/DDP cells. To determine the effect of miR-4486 overexpression on DDP resistance in HCT116/DDP and SW480/DDP cells, miR-4486 and NC mimics were synthesized. Firstly, the miR-4486 mimic or NC mimic were transfected into both cell lines before the expression level of miR-4486 was determined by RT-qPCR. The results indicated that miR-4486 expression was significantly promoted by the miR-4486 mimic (Fig. 2A). Subsequently, HCT116/DDP and SW480/DDP cells were transfected with the miR-4486 mimic or NC mimic and then treated with 5 and $11 \mu \mathrm{g} / \mathrm{ml}$ DDP, respectively, following which cell viability was subsequently detected using CCK-8 assay. The results showed that the overexpression of miR-4486 resulted in a significantly decreased cell viability compared with that in the DDP-only group (Fig. 2B). Next, the effect of miR-4486 on HCT116/DDP and SW480/DDP cell apoptosis was analyzed by flow cytometry (Fig. 2C). The results showed that the apoptosis rates of HCT116/DDP and SW480/DDP cells were significantly increased in the miR-4486 mimic group compared with those in the DDP-only group, suggesting that the overexpression of miR-4486 can promote the apoptosis of HCT116/DDP and SW480/DDP cells (Fig. 2D). These data demonstrated that the upregulation of miR-4486 can enhance the sensitivity of HCT116/DDP and SW480/DDP cells to DDP.

miR-4486 inhibits autophagy in HCT116/DDP and SW480/DDP cells. Western blotting was subsequently performed to assess the effect of miR-4486 on autophagy in HCT116/DDP and SW480/DDP cells. It was found that the expression levels of Beclin 1 and the ratio of LC3-II/LC3-I were significantly decreased in the miR-4486 mimic group compared with those in the DDP group (Fig. 3A-C), suggesting that the overexpression of miR-4486 can inhibit the occurrence of autophagy in HCT116/DDP and SW480/DDP cells. Furthermore, the number of autophagosomes was also reduced in the miR-4486 mimic group, which was in accordance with the expression levels of autophagy-related proteins (Fig. 3D). These aforementioned results suggest that miR-4486 can increase the DDP sensitivity of HCT116/DDP and SW480/DDP cells by preventing autophagy.

ATG7 is the direct target gene of miR-4486. Using the online tool TargetScan, the present study predicted that miR-4486 may directly target the 3'-UTR of ATG7 mRNA (Fig. 4A). To 
A

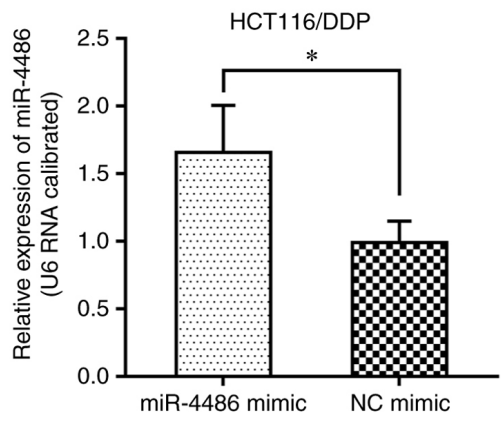

B
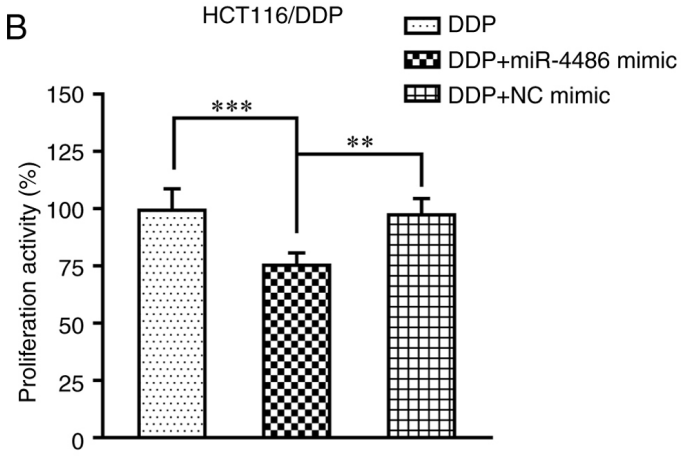

C
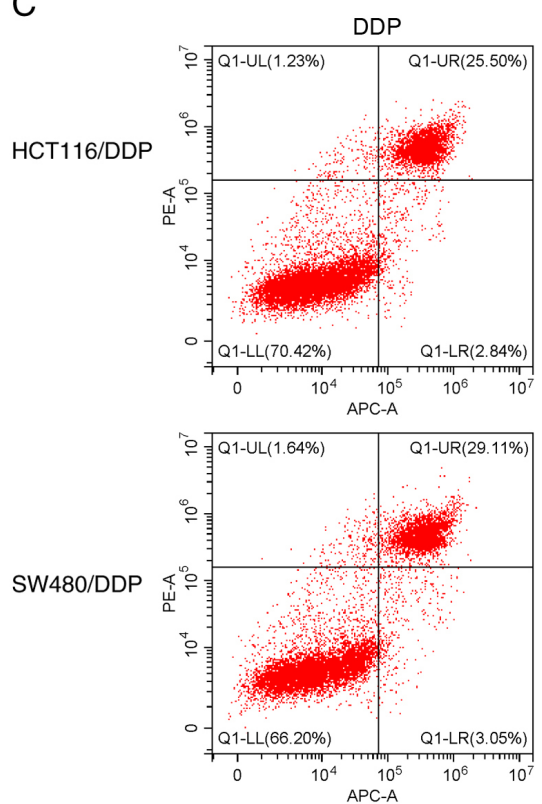

D HCT116/DDP

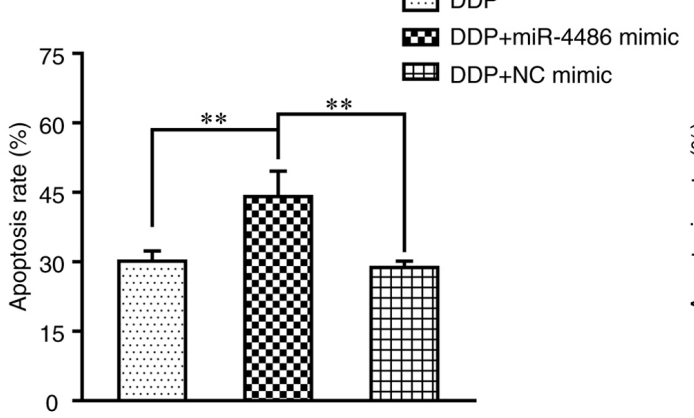

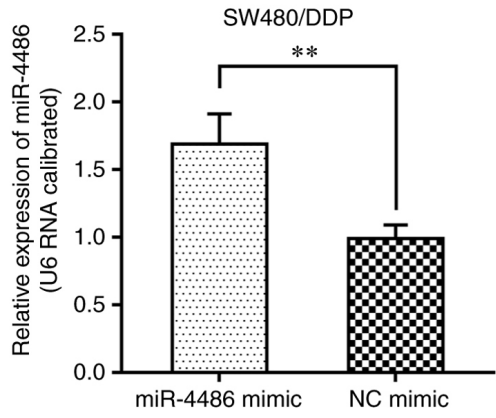

SW480/DDP

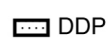

WDP+miR-4486 mimic

回 DDP+NC mimic
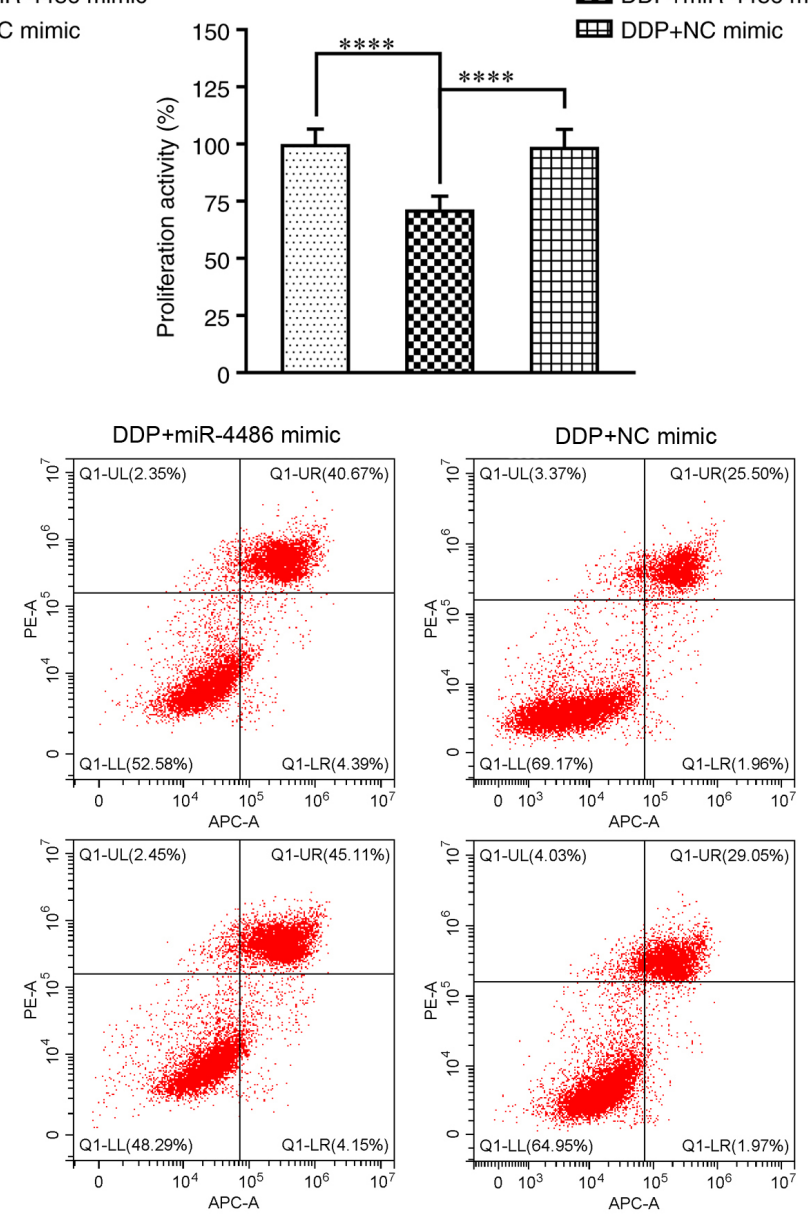

SW480/DDP

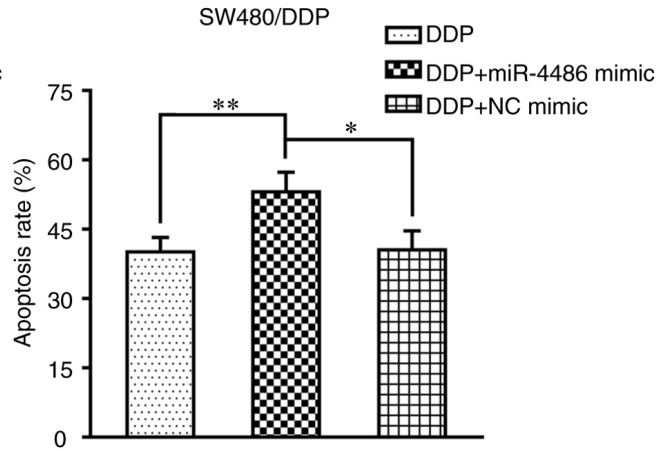

Figure 2. Overexpression of miR-4486 reverses the DDP resistance in HCT116/DDP and SW480/DDP cells. (A) DDP-resistant HCT116/DDP and SW480/DDP cells were transfected with miR-4486 mimic or NC mimic, before miR-4486 expression was measured by reverse transcription-quantitative PCR. Mimic NC served as a negative control. (B) HCT116/DDP and SW480/DDP cells were transfected with miR-4486 or NC mimic, followed by treatment with $5 \mu$ g/ml DDP. HCT116/DDP and SW480/DDP cell proliferation was observed by a Cell Counting Kit-8 assay. DDP group served as a control. (C) DDP-resistant HCT116 and SW480 cells were transfected with a miR-4486 or NC mimic before cell apoptosis was measured using flow cytometry assay, (D) which were quantified (The red dots in lower right quadrant of each flow cytometry diagram indicate apoptotic cells, and \% positive cells is noted on each quadrant). Bars represent the mean \pm standard deviation from $\geq$ three independent experiments. ${ }^{*} \mathrm{P}<0.05,{ }^{* *} \mathrm{P}<0.01,{ }^{* * *} \mathrm{P}<0.001$ and ${ }^{* * * * *} \mathrm{P}<0.0001$. miR, microRNA; DDP, cisplatin; $\mathrm{NC}$, negative control. 
A

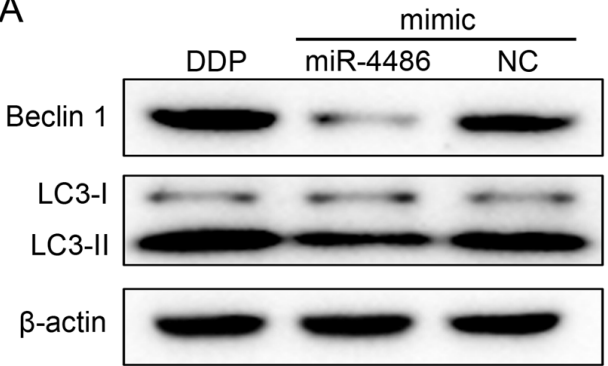

HCT116/DDP

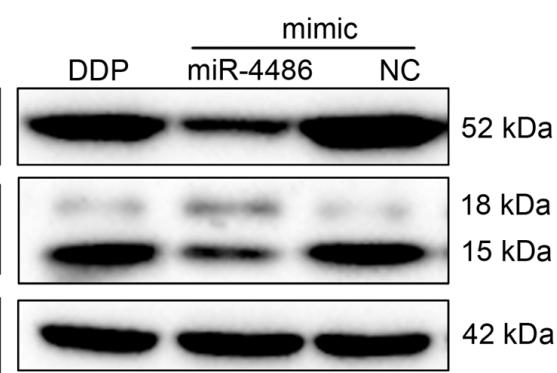

SW480/DDP

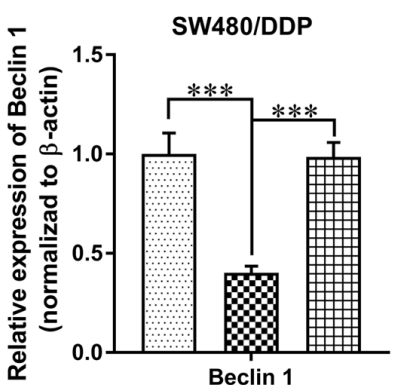

DDP

WD DP+miR-4486 mimic

DDP+NC mimic

C
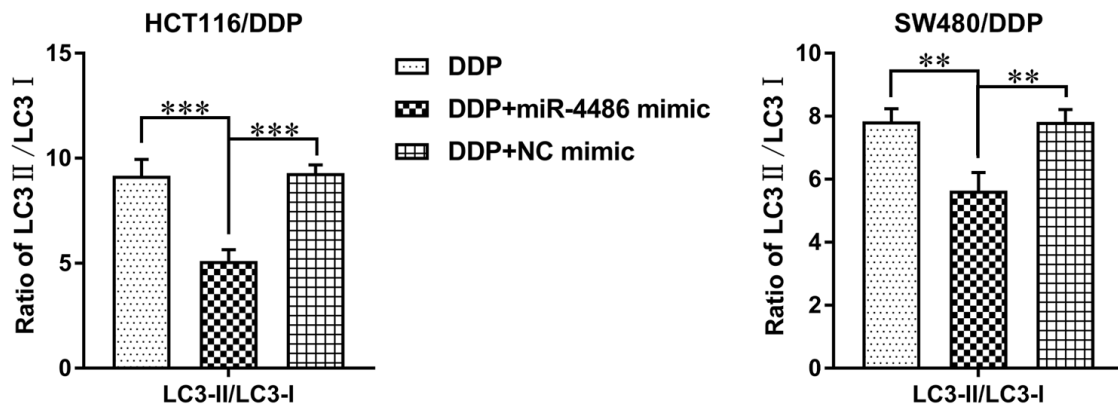

DDP

WDPtmiR-4486 mimic

DDP+NC mimic

D

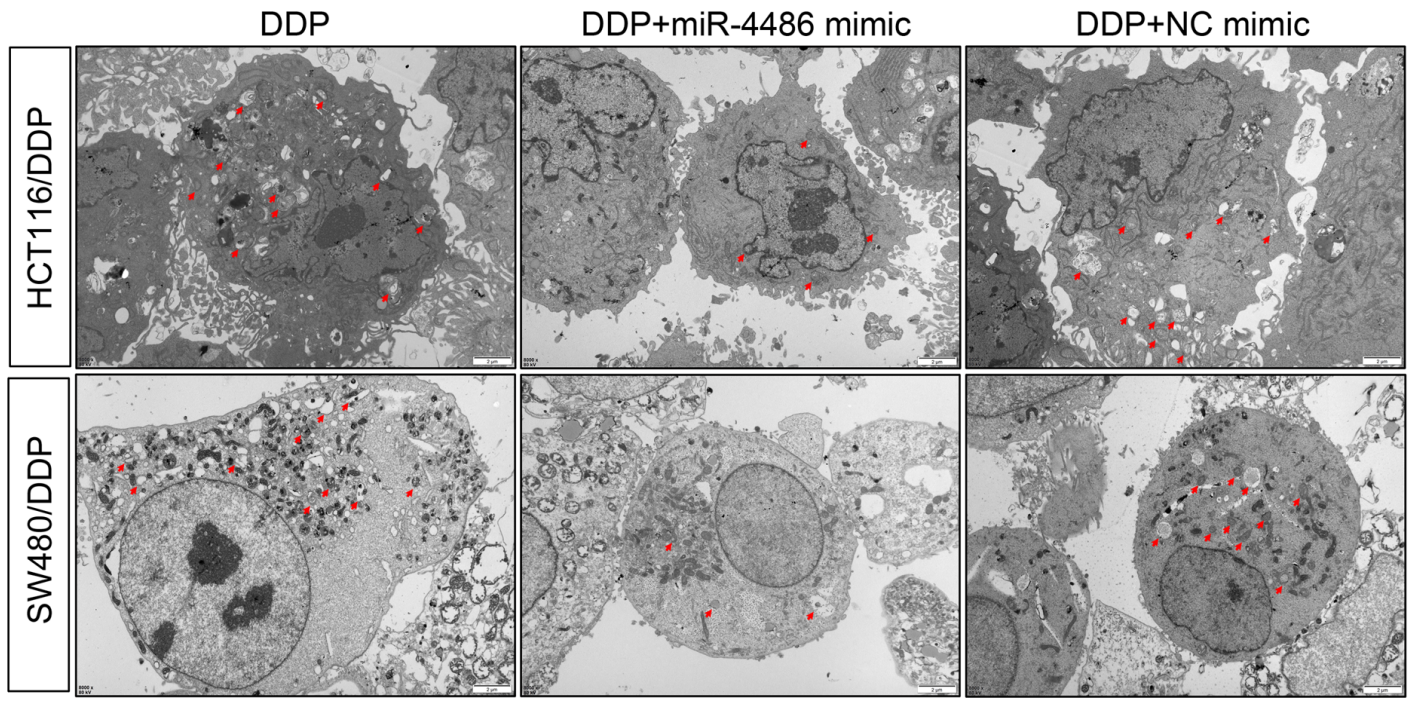

Figure 3. miR-4486 inhibits autophagy in HCT116/DDP and SW480/DDP cells. (A) DDP-resistant HCT116 and SW480 cells were transfected with miR-4486 mimic or negative control, and the protein expression of Beclin 1, LC3-I and LC3-II was analyzed by western blotting. (B) The relative expression level of Beclin 1 in the two cell lines was quantified. (C) The ratio of LC3-II/LC3-I in the two cell lines was calculated. (D) Autophagosomes in each group were observed by transmission electron microscopy at x8,000 magnification (scale bar, $2 \mu \mathrm{m}$ ). Red arrows indicate the autophagosomes. Bars represent the mean \pm standard deviation from $\geq$ three independent experiments. ${ }^{* *} \mathrm{P}<0.01$ and ${ }^{* * *} \mathrm{P}<0.001$. miR, microRNA; DDP, cisplatin; LC3, microtubule-associated proteins 1A/1B light chain 3B; NC, negative control.

verify this, Wt or Mut firefly luciferase reporters containing the 3'-UTR of ATG7 were constructed and luciferase assay was conducted. The results revealed that the miR-4486 mimic significantly decreased the luciferase activity of cells transfected with the ATG7 3'-UTR-Wt plasmid compared with that in the miR-4486 NC group but not in cells in the ATG7 
A

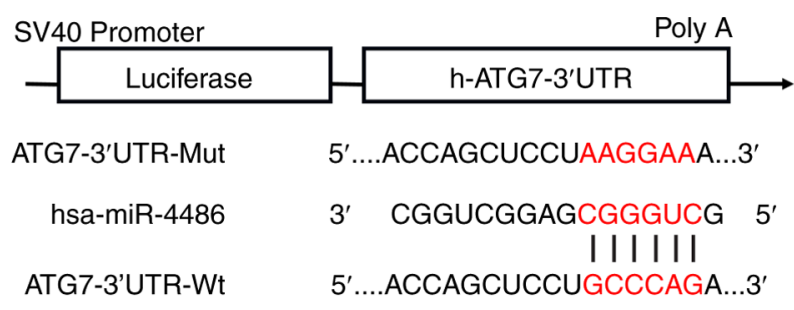

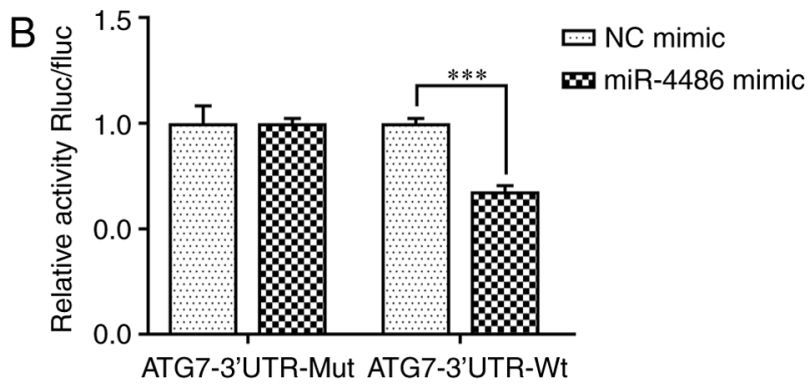
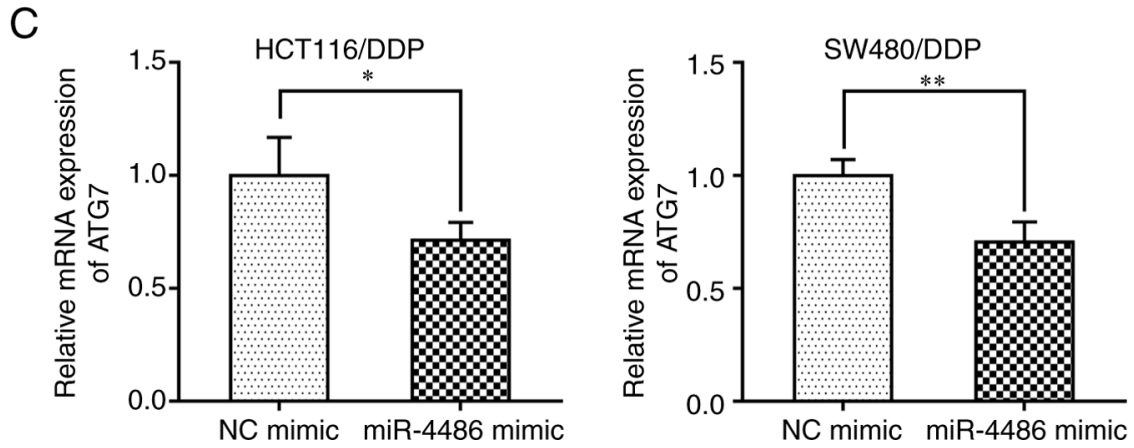

Figure 4. ATG7 is the direct target gene of miR-4486. (A) The predicted miR-4486-binding site existed in the 3'-UTR of ATG7 mRNA. (B) 293T cells were co-transfected with either miR-4486 or NC mimic and pSI-Check2-ATG7-3'-UTR-mut or pSI-Check2-ATG7-3'-UTR-wt plasmid. Relative firefly luciferase activity was measured at $48 \mathrm{~h}$ post-transfection. (C) The expression of ATG7 in HCT116/DDP and SW480/DDP cells transfected with miR-4486 mimic or NC mimic was detected by reverse transcription-quantitative PCR. Bars represent the mean \pm standard deviation from $\geq$ three independent experiments. $\mathrm{P}<0.05$, ${ }^{* *} \mathrm{P}<0.01,{ }^{* * *} \mathrm{P}<0.001$. ATG7, autophagy-related gene 7; UTR, untranslated region; miR, microRNA; DDP, cisplatin; NC, negative control; wt, wild-type; mut, mutant.

3'-UTR-Mut group (Fig. 4B). This suggests that miR-4486 may directly target ATG7 to reduce the expression of ATG7 by binding to its $3^{\prime}$-UTR. To verify further if the expression of ATG7 was regulated by miR-4486, the miR-4486 mimic or NC were transfected into HCT116/DDP and SW480/DDP cells, where RT-qPCR was conducted to detect the ATG7 expression levels. The data demonstrated that transfection with the miR-4486 mimic significantly reduced the ATG7 expression levels in HCT116/DDP and SW480/DDP cells compared with that in the NC mimic group (Fig. 4C). These results suggest that ATG7 is a target gene of miR-4486.

Overexpression of ATG7 reverses the effect of miR-4486 in HCT116/DDP and SW480/DDP cells. To further explore the role of ATG7, ATG7 was cloned into the pcDNA3.1 vector. HCT116/DDP and SW480/DDP cells were then transfected with pcDNA3.1-ATG7, where the RT-qPCR and WB results demonstrated that the mRNA and protein expression levels of ATG7 were both significantly higher in the pcDNA3.1-ATG7 group compared with those in the NC vector group (Fig. 5A and B).

Next, the miR-4486 mimic, pcDNA3.1-ATG7 or miR-4486 mimic + pcDNA3.1-ATG7 were transfected into HCT116/DDP and SW480/DDP cells treated with 5 and $11 \mu \mathrm{g} / \mathrm{ml}$ DDP, respectively, before cell viability was detected by CCK- 8 assay. The results showed that the overexpression of miR-4486 resulted in significantly reduced viability compared with that in the DDP group (Fig. 5C). By contrast, ATG7 overexpression partially but significantly increased the viability of miR-4486-overexpressing HCT116/DDP and SW480/DDP cells (Fig. 5C). Next, the expression levels of ATG7 and apoptosis-related proteins were analyzed by western blotting (Fig. 5D). Compared with that in the DDP group, the expression level of ATG7 was significantly decreased in the miR-4486 mimic group but significantly upregulated in the pcDNA3.1-ATG7 group (Fig. 5D). However, the trend in the expression of the pro-apoptotic protein cleaved caspase 3 was opposite to that found in ATG7, where the effects of miR-4486 mimic were significantly reversed by ATG7 overexpression (Fig. 5E and F). The trend of the Bcl-2/Bax ratio was in accordance with the trend of ATG7, where the ratio of $\mathrm{Bcl}-2 / \mathrm{Bax}$ was significantly decreased and increased by the miR-4486 mimic and pcDNA3.1-ATG7, respectively (Fig. 5G). The inhibitory effects of the miR-4486 mimic on the ratio of Bcl-2/Bax could be significantly reversed by ATG7 (Fig. 5G).

The expression of the autophagy-related proteins Beclin 1, LC3-I and LC3-II are shown in Fig. 5H. The levels of Beclin 1 and the LC3-II/LC3-I ratio in DPP-treated DPP-resistant cells were both significantly downregulated by the miR-4486 mimic but upregulated by pcDNA3.1-ATG7 transfection, whilst the overexpression of ATG7 could significantly reverse the inhibitory effects of the miR-4486 mimic on autophagy (Fig. 5I and J). Additionally, compared with that in the DDP group, the number of autophagosomes was reduced or increased after miR-4486 mimic or pcDNA3.1-ATG7 transfection, respectively. The number of autophagosomes was accordingly increased after pcDNA3.1-ATG7 transfection in the miR-4486 group (Fig. 5K). These data suggest that the overexpression of miR-4486 can reduce the viability of HCT116/DDP and SW480/DDP cells by reversing their DDP resistance. The role of miR-4486, which was found to promote apoptosis whilst inhibiting autophagy, may be associated with the inhibition of ATG7 expression. 

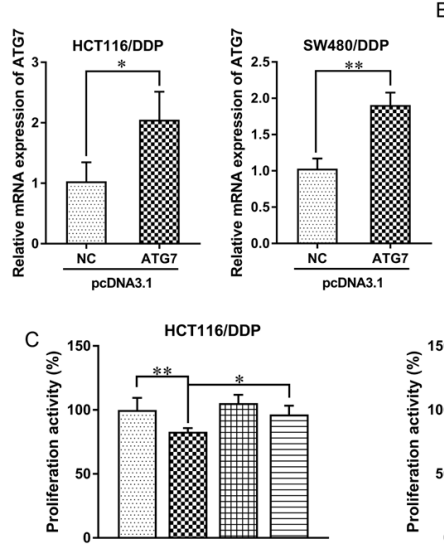

$\square$ DDP

OSDP+miR-4486 mimic

四 DDP+pcDNA3.1-ATG7

曰DDP+miR-4486 mimic+pcDNA3.1-ATG7

E
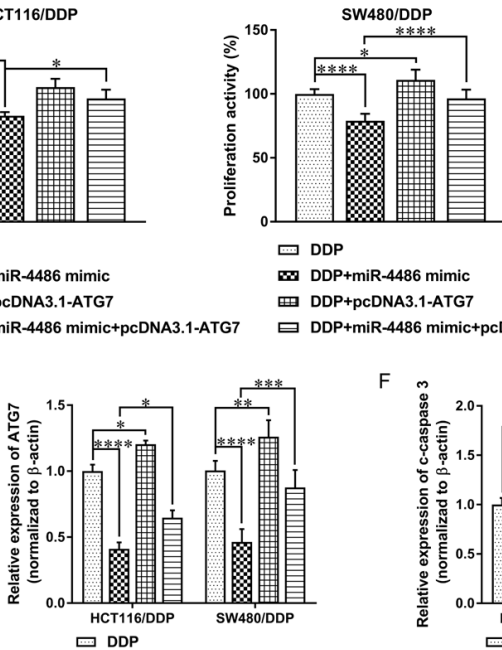

$\square$ DDP

DI DDP+miR-4486 mimic

DDP+pcDNA3.1-ATG7

曰DDP+miR-4486 mimic+pcDNA3.1-ATG7
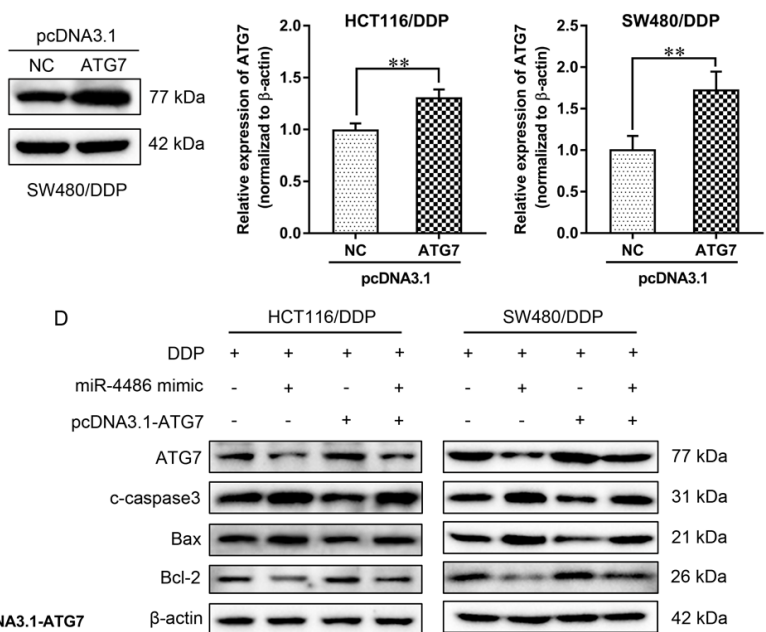

SW480/DDP
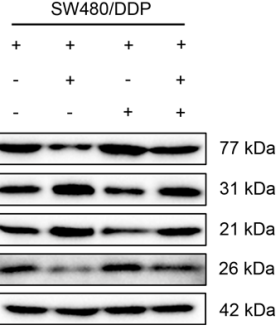

G
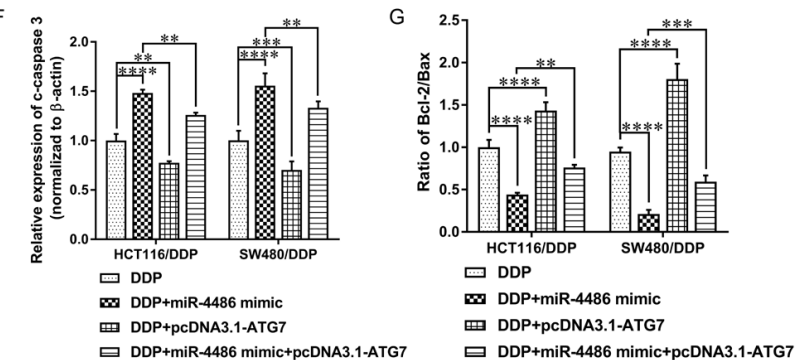

DDP

W0 DDP+miR-4486 mimic

DDP+miR-4486 mimic+pcDNA3.1-ATG

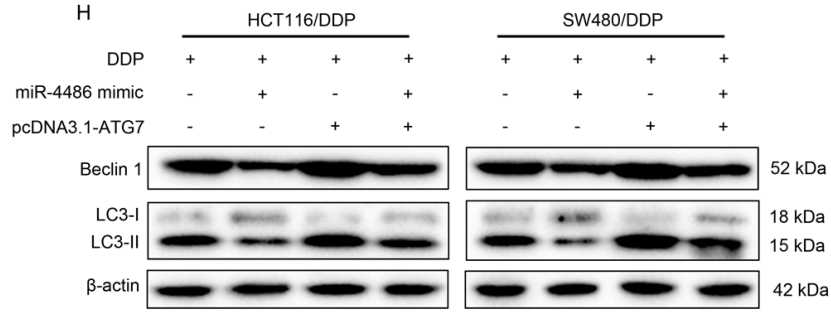

DDP

WI DDP+miR-4486 mimic

口 DDP+miR-4486 mimic+pcDNA3.1-ATG
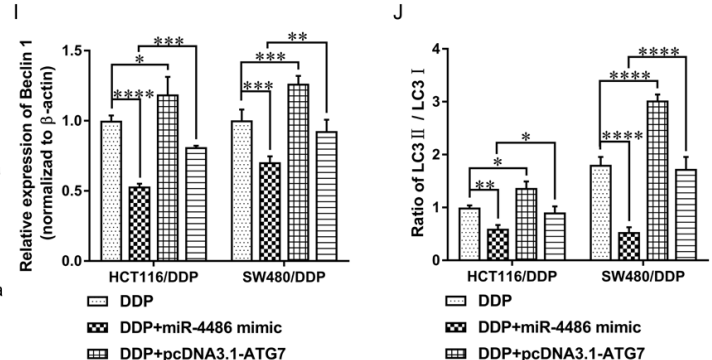

- DDP

曰DDP+miR-4486 mimic+pcDNA3.1-ATG7

K

DDP+miR-4486 mimic+pcDNA3.1-ATG7

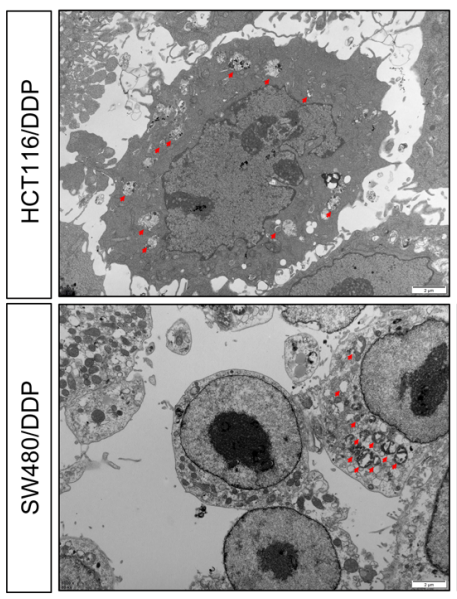

DDP+miR-4486 mimic

DDP+pcDNA3.1-ATG7

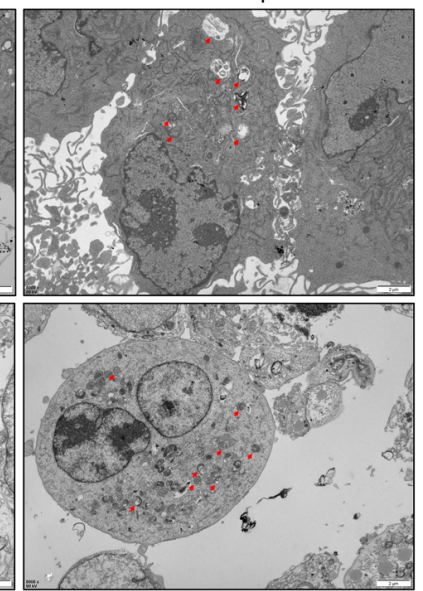

Figure 5. Overexpression of ATG7 reverses the effect of miR-4486 in HCT116/DDP and SW480/DDP cells. (A) mRNA expression of ATG7 was analyzed by reverse transcription-quantitative PCR. (B) The protein expression of ATG7 was measured and quantified by western blotting. (C) The viability of HCT116/DDP and SW480/DDP cells, which were transfected with miR-4486, pcDNA3.1-ATG7 or miR-4486 + pcDNA3.1-ATG7, was measured by Cell Counting Kit-8 assay. (D) The protein expression of ATG7 and the apoptosis-related proteins cleaved caspase 3, Bax and Bcl-2 in each group were measured by western blotting. (E) The levels of ATG7 protein expression were quantified. (F) The levels of cleaved caspase 3 protein were quantified. (G) The ratio of Bcl-2/Bax was calculated. (H) The protein expression of the autophagy-related proteins Beclin 1, LC3-I and LC3-II were analyzed by western blotting. (I) The expression of Beclin 1 was quantified. (J) The ratio of LC3-II/LC3-I was represented. DDP group served as a control. (K) Autophagosomes in each group were observed by transmission electron microscopy at x 8,000 magnification (scale bar, $2 \mu \mathrm{m}$ ). Red arrows indicate the autophagosomes. Bars represent the mean \pm standard deviation from $\geq 3$ independent experiments. ${ }^{*} \mathrm{P}<0.05,{ }^{* *} \mathrm{P}<0.01,{ }^{* * *} \mathrm{P}<0.001$ and ${ }^{* * * *} \mathrm{P}<0.0001$. ATG7, autophagy-related gene 7; miR, microRNA; DDP, cisplatin; autophagy-related gene 7; LC3, microtubule-associated proteins $1 \mathrm{~A} / 1 \mathrm{~B}$ light chain $3 \mathrm{~B}$. 


\section{Discussion}

The present study showed that the expression of miR-4486 was downregulated in DDP-resistant HCT116 and SW480 cells (HCT116/DDP and SW480/DDP) compared with that in their parental cell lines, HCT116 and SW480. In addition, the overexpression of miR-4486 could enhance the sensitivity of HCT116/DDP and SW480/DDP cells to DDP by inhibiting autophagy. Since ATG7 was reported to be an autophagy mediator (17), it was found that ATG7 was a regulatory target of miR-4486, where the promotion of apoptosis and inhibition of autophagy mediated by miR-4486 overexpression could be reversed by ATG7. The present study may provide novel insights into the role of miR-4486 in the autophagy-mediated DDP resistance in CC.

A number of miRNAs have been reported to be involved in regulating DDP-resistant tumor cells, such as osteosarcoma cells (22) and small-cell lung cancer cells (23). Some miRNAs reduced DDP resistance, whilst others can enhance DDP resistance. miR-133b was found to reduce DDP resistance, where its overexpression contributed to the suppression of the malignant proliferation and aggressiveness of DDP-resistant non-small cell lung cancer cells by targeting glutathione S-transferase $\pi 1$ (24). By contrast, cancer-associated fibroblasts-derived exosomal miR-196a conferred DDP resistance in head and neck cancer by targeting cyclin dependent kinase inhibitor 1B and inhibitor of growth family member 5 (25). The present study found that miR-4486 could reverse DDP resistance in HCT116/DDP and SW480/DDP cells by inhibiting cell viability and autophagy. Therefore, the underlying mechanism was explored further.

The chemotherapeutic agent DDP is a small-molecule platinum-containing compound that was originally found to inhibit bacterial growth (26). DDP was later reported to exert anticancer activity in a variety of tumors, including tumors of the ovaries and testes, breast, ovarian, testicular and lung $(27,28)$. It has also been reported that DDP inhibits tumor growth by inducing apoptosis; for example in the ovaries, testes and head and neck tumors (29). DDP remained the primary therapeutic option for several types of solid tumors, such as ovarian cancer, osteosarcoma and gastric cancer, despite its toxicity even at low doses, particularly in the kidneys and ear (30). CC is intrinsically resistant to DDP (31). However, the specific mechanism remains unclear. It has been reported that DDP causes ovarian cancer cell death by inducing apoptosis (29), such that a defect in apoptotic signaling could also confer DDP resistance. DDP-induced genotoxic stress activates multiple signal transduction pathways including those involving ATR, p53, p73 and MAPK, which can contribute to apoptosis or DDP resistance. The present study found that the expression of miR-4486 in HCT116/DDP and SW480/DDP cells was lower compared with that in their parental HCT116 and SW480 cells, whilst the overexpression of miR-4486 could markedly promote the apoptosis rates of HCT116/DDP and SW480/DDP cells after DDP treatment. These results suggest that the reduced expression of miR-4486 in HCT116/DDP and SW480/DDP cells may be involved in DDP resistance.

Autophagy, as a survival pathway that responds to metabolic stress, has been reported to mediate the acquired resistance phenotype of non-small-cell lung and breast cancer during chemotherapy $(5,32)$. Autophagy can regulate apoptosis, including mitophagy (33), microautophagy, chaperone-mediated autophagy $(34,35)$ and the interaction between Beclin 1 and antiapoptotic Bcl-2 family members $(36,37)$. When autophagosomes fuse with lysosomes to form autolysosomes, intra-autophagosomal LC3-II degrades their contents (38). Therefore, LC 3 could serve as a marker of autophagy. In addition, LC3 has also been reported to serve a pivotal role in the interaction between autophagy and apoptosis $(39,40)$. Beclin 1 regulates every major step in the autophagic pathway, from autophagosome formation to the maturation of autophagosomes/endosomes (41). It was previously found that the antitumor drug, cetuximab, could induce tumor cell apoptosis through the Beclin 1/LC3 autophagy pathway in CC (42). However, when tumor cells continued to divide and proliferate, but the surrounding environment cannot provide sufficient energy for maintaining the high levels metabolism, autophagy in tumor cells would be upregulated $(43,44)$. This is to adapt to any unfavorable conditions, including nutritional deficiencies, which can result in chemotherapeutic drug resistance and apoptosis suppression to increase the survival of tumor cells $(43,44)$. Protective autophagy is one of the main methods used by tumor cells to reduce the sensitivity to drugs, where the specific mechanism has been reported to involve the $\mathrm{PI} 3 \mathrm{~K} / \mathrm{AKT} / \mathrm{mTOR}$ and reactive oxygen species signaling pathways for resistance to erlotinib and gefitinib in non-small cell lung cancer (45) and to temozolomide in malignant glioma (46). A previous study has demonstrated that PI3K/AKT/mTOR signaling-mediated autophagy could lead to DDP resistance in CC (47). Therefore, inhibition of autophagy is an important therapeutic target for relieving DDP resistance in CC.

miRNAs that can regulate autophagy in multidrug-resistant CC cells have been found. For example, miR-409-3p was capable of enhancing the chemosensitivity of CC cells to oxaliplatin by inhibiting Beclin 1-mediated autophagy (48). By contrast, miR-153-5p promoted the sensitivity of CC cells to oxaliplatin by targeting the Bcl-2-mediated autophagy pathway (49). Therefore, the present study explored the role of miR-4486 on autophagy-mediated DDP resistance in CC cells. Notably, it was found that miR-4486 could downregulate the expression of Beclin 1, the ratio of LC3-II/I and the formation of autophagosomes to prevent autophagy in DPP-treated HCT116/DDP and SW480/DDP cells. This suggests that suppression of autophagy is part of the underlying mechanism in which miR-4486 can promote DDP-induced apoptosis in CC cells.

The present study demonstrated that the autophagy-related protein ATG7 was a direct inhibitory target of miR-4486 in autophagy-mediated DDP resistance in CC. A previous study observed the upregulation of ATG7 in DDP-resistant CC cells compared with sensitive $\mathrm{CC}$ cell lines, which participated in the autophagic survival and proliferation of CC cells (50). ATG7 was observed to be a key component of the autophagy machinery, with the main function of mediating the lipidation of the LC3/GABA type A receptor-associated protein during autophagosome formation (51). Furthermore, ATG7 was found to aggravate cell death in CC cell lines HCT116 and SW620, which could be inhibited by miR-106a (17). Another previous study showed that ATG7 is essential for autophagy activation, which significantly promotes dormant 
breast cancer cell survival and metastatic burden in vitro and in vivo (52). Accumulating evidence has reported the connection between DDP resistance during chemotherapy with dysregulations in miRNA expression $(17,53)$. However, the effect and mechanism of miR-4486 on DDP resistance in CC remain unclear. In the present study, the possible association between miR-4486 and ATG7 was first identified, which was verified using dual-luciferase reporter assay. Furthermore, it was found that ATG7 overexpression could reverse the inhibitory effects of miR-4486 on DDP resistance in HCT116/DDP and SW480/DDP cells, which in turn restored cell proliferation and autophagy. These data suggest further that miR-4486 can reduce DDP resistance in HCT116/DDP and SW480/DDP cells by targeting ATG7 to inhibit autophagy.

It should be noted the exact mechanism underlying these functions remain to be fully elucidated, since miR-4486 inhibitors and autophagy inhibitors were not used in the present study. The results of this study offered notable insight into the role of miR-4486, inhibitors of both miR-4486 and autophagy would need to be used to obtain a comprehensive conclusion.

In conclusion, results from the present study showed that overexpression of miR-4486 can decrease DDP resistance in HCT116/DDP and SW480/DDP cells by targeting ATG7 to inhibit viability and autophagy. Importantly, these findings suggested that miR-4486 may serve as a new therapeutic target in DDP-resistant CC.

\section{Acknowledgements}

Not applicable.

\section{Funding}

No funding was received.

\section{Availability of data and materials}

The datasets used and/or analyzed during the present study are available from the corresponding author on reasonable request.

\section{Authors' contributions}

QX conceived and designed the study. WW, LC and WZ performed the experiments. XH, LL, ZQ and KS were responsible for the collection, analysis and interpretation of the data. QX and LC confirm the authenticity of all the raw data. QX revised the manuscript critically for important intellectual content. All authors read and approved the final manuscript.

\section{Ethics approval and consent to participate}

The present study was approved by the local Ethics Committee at The Affiliated Hospital of Guangdong Medical University (Zhanjiang, China) and all patients provided written informed consent.

\section{Patient consent for publication}

Not applicable.

\section{Competing interests}

The authors declare that they have no competing interests.

\section{References}

1. Bray F, Ferlay J, Soerjomataram I, Siegel RL, Torre LA and Jemal A: Global cancer statistics 2018: GLOBOCAN estimates of incidence and mortality worldwide for 36 cancers in 185 countries. CA Cancer J Clin 68: 394-424, 2018.

2. Liu N, Wu C, Jia R, Cai G, Wang Y, Zhou L, Ji Q, Sui H, Zeng P, $\mathrm{XiaoH}$, et al: TraditionalChinese medicine combined with chemotherapy and cetuximab or bevacizumab for metastatic colorectal cancer: A randomized, double-blind, placebo-controlled clinical trial. Front Pharmacol 11:478, 2020.

3. Paldino E, Tesori V, Casalbore P, Gasbarrini A and Puglisi MA: Tumor initiating cells and chemoresistance: Which is the best strategy to target colon cancer stem cells? Biomed Res Int 2014: 859871, 2014

4. Duffy A, Le J, Sausville E and Emadi A: Autophagy modulation: A target for cancer treatment development. Cancer Chemother Pharmacol 75: 439-447, 2015.

5. Sui X, Chen R, Wang Z, Huang Z, Kong N, Zhang M, Han W, Lou F, Yang J, Zhang Q, et al: Autophagy and chemotherapy resistance: A promising therapeutic target for cancer treatment. Cell Death Dis 4: e838, 2013.

6. Devenport SN and Shah YM: Functions and implications of autophagy in colon cancer. Cells 8: 1349, 2019.

7. Di Leva G and Croce CM: miRNA profiling of cancer. Curr Opin Genet Dev 23: 3-11, 2013.

8. Aguda BD: Modeling microRNA-transcription factor networks in cancer. Adv Exp Med Biol 774: 149-167, 2013.

9. Baer C, Claus R and Plass C: Genome-wide epigenetic regulation of miRNAs in cancer. Cancer Res 73: 473-477, 2013.

10. Song B, Wang Y, Xi Y, Kudo K, Bruheim S, Botchkina GI, Gavin E, Wan Y, Formentini A, Kornmann M, et al: Mechanism of chemoresistance mediated by miR-140 in human osteosarcoma and colon cancer cells. Oncogene 28: 4065-4074, 2009.

11. Chai H, Liu M, Tian R, Li X and Tang H: miR-20a targets BNIP2 and contributes chemotherapeutic resistance in colorectal adenocarcinoma SW480 and SW620 cell lines. Acta Biochim Biophys Sin (Shanghai) 43: 217-225, 2011.

12. Guo Y, Pang Y, Gao X, Zhao M, Zhang X, Zhang H, Xuan B and Wang Y: MicroRNA-137 chemosensitizes colon cancer cells to the chemotherapeutic drug oxaliplatin (OXA) by targeting YBX1. Cancer Biomarkers 18: 1-9, 2017.

13. Qu J, Zhao L, Zhang P, Wang J, Xu N, Mi W, Jiang X, Zhang C and Qu J: MicroRNA-195 chemosensitizes colon cancer cells to the chemotherapeutic drug doxorubicin by targeting the first binding site of BCL2L2 mRNA. J Cell Physiol 230: 535-545, 2015.

14. Liu J, Cheng LG and Li HG: LncRNA SNHG20 promoted the proliferation of glioma cells via sponging miR-4486 to regulate the MDM2-p53 pathway. Eur Rev Med Pharmacol Sci 23: 5323-5331, 2019.

15. Asensio VJ, Tomás A, Iglesias A, de Llano LP, Del Pozo V and Cosío BG; CHACOS study group: Eosinophilic COPD patients display a distinctive serum mirna profile from asthma and non-eosinophilic COPD. Arch Bronconeumol (Engl ED) 56: 234-241, 2020 (In English, Spanish).

16. Kim SH, Yun SW, Kim HR and Chae SA: Exosomal microRNA expression profiles of cerebrospinal fluid in febrile seizure patients. Seizure 81: 47-52, 2020.

17. Hao H, Xia G, Wang C, Zhong F, Liu L and Zhang D: miR-106a suppresses tumor cells death in colorectal cancer through targeting ATG7. Med Mol Morphol 50: 76-85, 2017.

18. Xie Q, Liu Y and Li X: The interaction mechanism between autophagy and apoptosis in colon cancer. Transl Oncol 13: 100871, 2020.

19. Benson AB III, Venook AP, Cederquist L, Chan E, Chen YJ, Cooper HS, Deming D, Engstrom PF, Enzinger PC, Fichera A, et al: Colon cancer, version 1.2017, NCCN clinical practice guidelines in oncology. J Natl Compr Canc Netw 15: 370-398, 2017.

20. Bosman FT, Carneiro F, Hruban RH and Theise ND (eds.): WHO Classification of Tumors of the Digestive System. Vol 3. 4th edition. IARC Press, Lyon, 2010. 
21. Livak KJ and Schmittgen TD: Analysis of relative gene expression data using real-time quantitative PCR and the 2(-Delta Delta C(T)) method. Methods 25: 402-408, 2001.

22. Song L, Zhou Z, Gan Y, Li P, Xu Y, Zhang Z, Luo F, Xu J, Zhou Q and Dai F: Long noncoding RNA OIP5-AS1 causes cisplatin resistance in osteosarcoma through inducing the LPAATbeta/PI3K/AKT/mTOR signaling pathway by sponging the miR-340-5p. J Cell Biochem 120: 9656-9666, 2019.

23. Pan B, Chen Y, Song H, Xu Y, Wang R and Chen L: Mir-24-3p downregulation contributes to VP16-DDP resistance in small-cell lung cancer by targeting ATG4A. Oncotarget 6: 317-331, 2015.

24. Lin C, Xie L, Lu Y, Hu Z and Chang J: miR-133b reverses cisplatin resistance by targeting GSTP1 in cisplatin-resistant lung cancer cells. Int J Mol Med 41: 2050-2058, 2018.

25. Qin X, Guo H, Wang X, Zhu X, Yan M, Wang X, Xu Q, Shi J, Lu E, Chen W and Zhang J: Exosomal miR-196a derived from cancer-associated fibroblasts confers cisplatin resistance in head and neck cancer through targeting CDKN1B and ING5. Genome Biol 20: 12, 2019.

26. Chan H, Pearson CS, Green CM, Li Z, Zhang J, Belfort G, Shekhtman A, Li H and Belfort M: Exploring intein inhibition by platinum compounds as an antimicrobial strategy. J Biol Chem 291: 22661-22670, 2016.

27. Dasari S and Tchounwou PB: Cisplatin in cancer therapy: Molecular mechanisms of action. Eur J Pharmacol 740: 364-378, 2014.

28. Sun CY, Zhang QY, Zheng GJ and Feng B: Phytochemicals: Current strategy to sensitize cancer cells to cisplatin. Biomed Pharmacother 110: 518-527, 2019.

29. Siddik ZH: Cisplatin: Mode of cytotoxic action and molecular basis of resistance. Oncogene 22: 7265-7279, 2003.

30. Oun R, Moussa YE and Wheate NJ: Correction: The side effects of platinum-based chemotherapy drugs: A review for chemists. Dalton Trans 47: 7848, 2018.

31. Köberle B, Tomicic MT, Usanova S and Kaina B: Cisplatin resistance: Preclinical findings and clinical implications. Biochim Biophys Acta 1806: 172-182, 2010.

32. Wu WK, Coffelt SB, Cho CH, Wang XJ, Lee CW, Chan FK, $\mathrm{Yu} \mathrm{J}$ and Sung JJ: The autophagic paradox in cancer therapy. Oncogene 31: 939-953, 2012

33. Wang K: Autophagy and apoptosis in liver injury. Cell Cycle 14: 1631-1642, 2015.

34. Bursch W: The autophagosomal-lysosomal compartment in programmed cell death. Cell Death Differ 8: 569-581, 2001.

35. Shimizu S, Kanaseki T, Mizushima N, Mizuta T, Arakawa-Kobayashi S, Thompson CB and Tsujimoto Y: Role of Bcl-2 family proteins in a non-apoptotic programmed cell death dependent on autophagy genes. Nat Cell Biol 6: 1221-1228, 2004

36. He C and Levine B: The beclin 1 interactome. Curr Opin Cell Biol 22: 140-149, 2010.

37. Itakura $\mathrm{E}$, Kishi $\mathrm{C}$, Inoue $\mathrm{K}$ and Mizushima N: Beclin 1 forms two distinct phosphatidylinositol 3-kinase complexes with mammalian Atg14 and UVRAG. Mol Biol Cell 19: 5360-5372, 2008.

38. Deretic V: Autophagosome and phagosome.Methods MolBiol445: $1-10,2008$

39. Fu Ll, Cheng Y and Liu B: Beclin-1: Autophagic regulator and therapeutic target in cancer. Int J Biochem Cell Biol 45: 921-924, 2013.
40. Noguchi M, Hirata N, Tanaka T, Suizu F, Nakajima H and Chiorini JA: Autophagy as a modulator of cell death machinery. Cell Death Dis 11: 517, 2020

41. Kang R, Zeh HJ, Lotze MT and Tang D: The Beclin 1 network regulates autophagy and apoptosis. Cell Death Differ 18: 571-580, 2011.

42. Guo GF, Wang YX, Zhang YJ, Chen XX, Lu JB, Wang HH, Jiang C, Qiu HQ and Xia LP: Predictive and prognostic implications of 4E-BP1, Beclin-1, and LC3 for cetuximab treatment combined with chemotherapy in advanced colorectal cancer with wild-type KRAS: Analysis from real-world data. World J Gastroenterol 25: 1840-1853, 2019.

43. Guo JY, Xia B and White E: Autophagy-mediated tumor promotion. Cell 155: 1216-1219, 2013.

44. Bellodi C, Lidonnici MR, Hamilton A, Helgason GV, Soliera AR, Ronchetti M, Galavotti S, Young KW, Selmi T, Yacobi R, et al: Targeting autophagy potentiates tyrosine kinase inhibitor-induced cell death in Philadelphia chromosome-positive cells, including primary CML stem cells. J Clin Invest 119: 1109-1123, 2009.

45. Li H, Jin X, Zhang Z, Xing Y and Kong X: Inhibition of autophagy enhances apoptosis induced by the PI3K/AKT/mTor inhibitor NVP-BEZ235 in renal cell carcinoma cells. Cell Biochem Funct 31: 427-433, 2013.

46. Lin CJ, Lee CC, Shih YL, Lin TY, Wang SH, Lin YF and Shih CM: Resveratrol enhances the therapeutic effect of temozolomide against malignant glioma in vitro and in vivo by inhibiting autophagy. Free Radic Biol Med 52: 377-391, 2012.

47. Chen X, Xu H, Yu X, Wang X, Zhu X and Xu X: Apigenin inhibits in vitro and in vivo tumorigenesis in cisplatin-resistant colon cancer cells by inducing autophagy, programmed cell death and targeting $\mathrm{m}-\mathrm{TOR} / \mathrm{PI} 3 \mathrm{~K} / \mathrm{Akt}$ signalling pathway. J BUON 24: 488-493, 2019.

48. Tan S, Shi H, Ba M, Lin S, Tang H, Zeng X and Zhang X: miR-409-3p sensitizes colon cancer cells to oxaliplatin by inhibiting Beclin-1-mediated autophagy. Int J Mol Med 37: 1030-1038, 2016.

49. He Y, Zhang L, Tan F, Wang LF, Liu DH, Wang RJ and Yin XZ: MiR-153-5p promotes sensibility of colorectal cancer cells to oxaliplatin via targeting Bcl-2-mediated autophagy pathway. Biosci Biotechnol Biochem 84: 1645-1651, 2020.

50. Cernigliaro C, D'Anneo A, Carlisi D, Giuliano M, Gammazza AM, Barone R, Longhitano L, Cappello F, Emanuele S and Distefano A: Ethanol-mediated stress promotes autophagic survival and aggressiveness of colon cancer cells via activation of Nrf2/HO-1 pathway. Cancers (Basel) 11: 505, 2019.

51. Schaaf MB, Keulers TG, Vooijs MA and Rouschop KM: LC3/GABARAP family proteins: autophagy-(un)related functions. FASEB J 30: 3961-3978, 2016.

52. Vera-Ramirez L, Vodnala SK, Nini R, Hunter KW and Green JE: Autophagy promotes the survival of dormant breast cancer cells and metastatic tumour recurrence. Nat Commun 9: 1944, 2018.

53. Ma J, Dong C and Ji C: MicroRNA and drug resistance. Cancer Gene Ther 17: 523-531, 2010

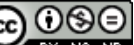

This work is licensed under a Creative Commons Attribution-NonCommercial-NoDerivatives 4.0 International (CC BY-NC-ND 4.0) License. 